\title{
Poetica medievale tra Oriente e Occidente, a cura di Paolo Bagni e Maurizio Pistoso
}

\section{G. Matteo Roccati}

\section{Q OpenEdition}

1 Journals

\section{Edizione digitale}

URL: http://journals.openedition.org/studifrancesi/34197

DOI: 10.4000/studifrancesi.34197

ISSN: 2421-5856

\section{Editore}

Rosenberg \& Sellier

\section{Edizione cartacea}

Data di pubblicazione: 1 novembre 2005

Paginazione: 384-385

ISSN: 0039-2944

\section{Notizia bibliografica digitale}

G. Matteo Roccati, «Poetica medievale tra Oriente e Occidente, a cura di Paolo Bagni e Maurizio Pistoso», Studi Francesi [Online], 146 (XLIX | II) | 2005, online dal 30 novembre 2015, consultato il 19 avril 2021. URL: http://journals.openedition.org/studifrancesi/34197 ; DOI: https://doi.org/10.4000/studifrancesi. 34197

Questo documento è stato generato automaticamente il 19 avril 2021.

\section{(c) (1)}

Studi Francesi è distribuita con Licenza Creative Commons Attribuzione - Non commerciale - Non opere derivate 4.0 Internazionale. 
Poetica medievale tra Oriente e Occidente, a cura di Paolo Bagni e Maurizio Pistoso

G. Matteo Roccati 


\section{NOTIZIA}

Poetica medievale tra Oriente e Occidente, a cura di PAOLO BAGNI e MAURIZIO PISTOSO, Roma, Carocci Editore («Biblioteca medievale / Saggi», 11), 2003, pp. 322.

1 Il volume raccoglie gli atti del convegno «Poetica medievale. Confronti e incontri: tradizione arabo-islamica e tradizione occidentale» (Bologna, 11-13/5/2000), comprende una ventina di contributi tra i quali i seguenti sono più direttamente interessanti per il nostro ambito.

2 Antonio PIOLETTI, Della tipologia della cornice narrativa, pp. 13-27 (con riferimenti, fra gli altri, a Barlaam et Josaphat, a Apollonio di Tiro e alla Queste del Saint Graal). Daniela MENEGHINI, "Tajnis e annominatio»: precetti retorici nella tradizione persiana e nella tradizione occidentale, pp. 97-109 (sulle Artes poeticae del XII-XIII secolo). Paolo BAGNI, Il reticolo del dicibile nelle arti poetiche latino-medievali, pp. 111-121. Francesco STELLA, Poetica ed esegesi: creatività e legittimazione culturale nella poesia mediolatina, pp. 139-159. Daniela BOcCASSINI, Il cavaliere falconiere: percorsi di un'immagine tra Oriente e Occidente (VI-XIII secolo), pp. 161-187 (sui legami nell'iconografia tra l'Iran e la Sicilia normanna). Maurizio PISTOSo, Passaggi di segni. Qualche percezione dell'Occidente medievale nella cultura letteraria e figurativa persiana, pp. 189-203. Abdelfattah кіLITO, Averroès et la «Poétique», pp. 205-209. Mario MANcinI, Petrarca e la poetica degli Arabi, pp. 211-221. Maria Rosa MENOCAL, Culture in Time of Tolerance: al-Andalus as a Model for our own Time, pp. 233-244. Julie Scott MeISAmI, Between Arabia and al-Andalus: Nostalgia as an Arabic Poetic Genre, pp. 245-257. Giovanna LELLI, Elementi per una poetica comparata del Mediterraneo medievale, pp. 293-303. 